\title{
Commentary: what's the problem?
}

\author{
Bertie Leigh
}

Hempsons Solicitors, London WC2N 6NJ Bertie Leigh senior partne mamsl@ hempsons.co.uk
Brian Capstick's views will come as a surprise to people who suppose that negligence litigation is out of control or a large burden to the NHS. As he shows, it costs well under $1 \%$ of turnover, and most of that is the cost of caring for birth injured children, a bill that ought to be met under any system. Given that there are 850000 adverse events causing harm, 6000 claims seems modest.

The volume of claims is also falling. Making Amends noted that it had fallen in two successive years from a peak of 8000 . The Legal Services Commission's new evidence to the chief medical officer's inquiry is that last year they issued only 6000 new certificates and closed 8000 files. This compares with 18000 new certificates at the peak in 1991. Since $55 \%$ of certificates do not result in writs being issued, it is likely that only 2700 new writs will be issued next year.

\section{Time and costs}

Capstick refers to the problem of cases that take over five years to resolve as highlighted in the 2001 National Audit Office report. ${ }^{1}$ The chairman of the Public Accounts Committee in parliament described this as an almost systematic lack of compassion. However, the report looked only at an atypical group of cases: those concerning events before 1995 and closed in 2000. It ignored the cases closed before 2000 and the fact that the legal system changed in 1998. In November 2003, the Litigation Authority announced that the resolution time for cases under $£ 30000$ had fallen to eight months. This means the average case is now settled under English tort law faster than it is settled under the New Zealand no fault scheme.

Nor is it true that that much money could be saved by mediation. About $98 \%$ of claims are settled without going to trial, virtually all of them by simple negotiation or a payment into court, both of which are much quicker and cheaper than mediation.

Today the English system provides a swift and reasonably robust means of disposing of a modest volume of claims. Any alternative is likely to expand the number of cases. Capstick is surely right when he says that publicising a system in which there is no penalty for a spurious claim would attract a much larger proportion of the 850000 who are harmed. There are good arguments for expanding the compensation culture, but those against seem more popular.

When liability is conceded in the redress scheme, lawyers will be engaged by many claimants anxious to maximise the value of the concession made. Obviously, legal fees for disputing liability can be avoided if liability is conceded at the start, but far more arguments about the amount of compenasation will exhaust any savings.

Competing interests: $\mathrm{BL}$ is senior partner at a firm of solicitors that specialises in advising the healthcare professions and the NHS.

1 National Audit Office. Handling clinical negligence claims in England. London: Stationery Office, 2001. (HC 403 2000-2001).

\section{Pride comes ...}

To supplement both my income and my experience, I, like many junior hospital doctors in London in the late 1960s, did odd surgeries for general practitioners at weekends and some emergency home visits then and at night. The latter were telephoned through to my home in Dulwich. Single visits were poor value, as you got considerably less than the general practitioner was reimbursed, but you might get a run of visits, telephoning in after each one. They meant driving all over south London, from the inner slums and housing estates to the leafy suburbs and beyond, to Kent. Travelling under the aegis of a doctor's medical bag was then relatively safe, although it provoked attempted theft later. I felt really threatened only once, when approached aggressively by two policemen in a patrol car when I had stopped in a deserted shopping street at 3 am to use a public telephone. Thinking they were definitely on to a criminal, they were reluctant to change their minds.

This particular summons was to a young man with a stiff neck, seen inconclusively both by an emergency doctor and in an accident and emergency department. He was allegedly deteriorating. The caller was querying meningitis. I set out to Docklands. The address was in a largely deserted and boarded up, soon to be demolished, row of ancient tenement buildings, erected in the previous century by a charitable trust. They were dank, dark, and silent except for the drip and trickle of overflow pipes leaking from a great height. With some difficulty I located the right building, entered, mounted a decrepit stone staircase in appalling light, and found the flat I needed. I was greeted effusively and with great deference by an Asian immigrant concerned about his son.

The young man was lying in the shadow of a single low-powered bulb, in a bed with no sheets. He did indeed have a stiff neck. Rhythmically it went into involuntary spasm, pulling his head backwards on to his pillow-spasmodic retrocollis, an extrapyramidal syndrome. He had chronic schizophrenia and was receiving depot injections at a clinic to control it. I explained to the father that, although distressing, the spasms were not a serious threat to his son and that they were caused by his medication. This would need adjusting by those managing it, whom he should contact for advice when he could.

I left the tenement flat a transiently heroic figure-one up on two other doctors in my diagnosis, explanation, and management, and with the flowery and elaborate compliments and thanks of the father ringing in my ears. Missing the top step off the darkened passage, I skidded and crashed all the way down the first flight of stairs, my precious status symbol, the medical bag, thumping and bumping alongside to join me in a heap at the bottom. Shaken, and suitably chastened, I picked myself up and made a bruised withdrawal towards the dimly visible exit-enriched by a few shillings and by an unforgettable experience.

Hugh Tunstall-Pedoe director, Cardiovascular Epidemiology Unit, University of Dundee 